\title{
PENGARUH PEMBELAJARAN JARAK JAUH DENGAN APLIKASI GOOGLE CLASS TERHADAP HASIL BELAJAR MAHASISWA
}

\author{
Niken Septantiningtyas ${ }^{1}$ \\ Universitas Nurul Jadid Paiton Probolinggo
}

\section{Info Artikel \\ Sejarah Artikel: Diterima; Oktober 2018 Disetujui; Desember 2018 Dipublikasikan; Januari 2019}

Keywords:

google class, distance learning, curriculum development

\begin{abstract}
This research is an application of research in accordance with the learning trend 4.0, namely the application of Online Applications as IT-Based Learning Media that has been developed by Google. Google class is an application of research developed with the theme of learning the Industrial Revolution 4.0, which is an application of an online-based application for students in conducting online lectures, this application can facilitate students on assignments given by lecturers to be done anywhere and anytime, this application also can make it easier for students to communicate online directly with lecturers who need a subject without having to exit the google class application, other than that in this application students can have discussions with friends in the same class to program the course. The google class application is used to facilitate communication between lecturers and students online and directly on the topic of the chapter being studied so that students better understand the aims and objectives desired by the lecturer. This study is a research that seeks a relationship between the application of distance learning using the Google class application with student learning outcomes, this is a quantitative study of research data tested with normality test, homogeneity test and hypothesis test. The research will be conducted in the even semester of the 2018-2019 school year in the sixth semester students at Nurul Jadid University.
\end{abstract}




\section{PENDAHULUAN}

Pada saat ini dunia tengah memasuki era revolusi industri 4.0. atau revolusi industri dunia ke-empat dimana teknologi telah menjadi basis dalam kehidupan manusia. Segala hal menjadi tanpa batas dan tidak terbatas akibat perkembangan internet dan teknologi digital. Era ini telah mempengaruhi banyak aspek kehidupan baik di bidang ekonomi, politik, kebudayaan, seni, dan bahkan sampai ke dunia pendidikan (Abdurahman, 2017). Hubungan dunia pendidikan dengan revolusi industri 4.0. adalah dunia pendidikan dituntut harus mengikuti perkembangan teknologi yang sedang berkembang pesat serta memanfaatkan teknologi informasi dan komunikasi sebagai fasilitas lebih dan serba canggih untuk memperlancar proses pembelajaran. Selain itu, diharapkan dengan pemanfaatan teknologi informasi dan komunikasi pola pikir pembelajaran dapat bergeser dari berpusat pada guru (teacher centered) menjadi berpusat pada peserta didik (student centered). Menurut (Amalia, Farah Fadhilah \& Rachmawati, Rini, 2013) Teknologi informasi dan komunikasi mutakhir telah berhasil menembus batas antar benua di seluruh dunia. Selain itu memungkinkan untuk peningkatan kualitas pendidikan, perangkat lunak pendidikan yang interaktif adalah jalan untuk memperkaya pendidikan dengan mengintegrasikan teknologi ke dalam kelas tradisional. Selain itu, teknologi merupakan sumber daya yang bagus bagi guru sebagai penunjang dalam proses pengajaran dan pembelajaran.

Teknologi dalam dunia pendidikan biasanya disebut e-learning. Manfaat dari pemakaian fasilitas dari e-learning adalah untuk memperlancar proses belajar dan pembelajaran. Melalui E-Learning, belajar tidak lagi dibatasi oleh ruang dan waktu. Belajar dapat dilakukan kapan saja dan dimana saja. (Budiana, 2015) Secara umum ada dua faktor yang mempengaruhi hasil belajar yaitu faktor internal dan faktor internal. Minat belajar termasuk dalam faktor internal memiliki hubungan erat terhadap hasil belajar. Hal ini berarti selain dampak positif terhadap hasil belajar, penggunaan teknologi dalam pembelajaran dapat berdampak positif pada minat belajar dan (Budiman, 2017). Teknologi dapat meningkatkan kualitas dan jangkauan apabila digunakan secara bijak untuk pendidikan dan latihan, dan mempunyai arti yang sangat penting bagi kesejahteraan. Menurut (Satya, 2014) " Penggunaan teknologi diharapkan dapat meningkatkan minat belajar mahasiswa karena proses pembelajaran yang bersifat konvensional dirasa kurang menyenangkan dan terbilang monoton". Selain itu, pembelajaran yang hanya berpusat pada dosen dan buku akan membuat mahasiswa bosan dengan pembelajaran di kelas. Oleh karena itu, diperlukan suatu inovasi pembelajaran salah satunya dengan pembelajaran yang berbasis teknologi agar tampilan dan gaya belajar menjadi lebih menarik, membuat siswa terhindar dari rasa jenuh dan bosan saat mengikuti pembelajaran. Hasil penelitian Muali, dkk yang menunjukkan bahwa pembelajaran yang berbasis teknologi sangat membantu siswa dalam memahami pembelajaran secra lebih baik (Muali et al., 2018).

Salah satu teknologi pembelajaran yang dapat digunakan adalah pembelajaran berbasis android, dimana mahasiswa dapat menggunakan aplikasi android dan kontennya dalam proses pembelajaran mereka, salah satu aplikasi online yang dapat diunduh di play store secara online untuk mempermudah tugas tugas mahasiswa adalah aplikasi "google class". Aplikasi ini adalah aplikasi rancangan google yang bisa kita gunakan langsung dengan mendowloadnya di aplikasi adroid play store, hampir semua mahasiswa memiliki smartphone android sehingga dalam penerapannya dapat dilaksanakan. Dalam mata kuliah pengembangan kurikulum mahasiswa di tuntut untuk dapat mencapai standar kompetensi keberhasilan sesuai silabus salah satunya adalah merancang kurikulum untuk tingkat satuan pendidikan, oleh karena itu banyak contoh kurikulum dari tahun ke tahun yang harus mereka kaji agar mereka memahami dasar dasar pengembangan kurikulum tersebut, contoh contoh kurikulum tersebut banyak yang di muat dalam bentuk file baik ms word maupun pdf, sehingga untuk menghemat kertas tidak semua contoh kurikulum tersebut harus mereka print karena begitu banyaknyanya halaman yang harus dicetak, dosen memberikan beberapa file pada mahasiswa untuk mereka kaji kembali dan menganalisis dasar -dasar pengembangan kurikulum. Proses pembelajaran ini akan berjalan dengan baik bila disertai dengan minat, oleh karena itu seorang dosen perlu membangkitkan minat mahasiswanya agar pelajaran yang diberikan mudah untuk dipahami. Selain itu, menurut (Slameto, 2010) "berdasarkan hasil penelitian psikologi menunjukkan bahwa kurangnya minat belajar dapat mengakibatkan kurangnya ketertarikan pada 
suatu bidang tertentu dan tentunya akan sangat mempengaruhi hasil akhir dari proses pembelajaran. Oleh karena itu dari permasalahan di atas mendorong penulis untuk meneliti "Pengaruh penerapan Pembelajaran Jarak Jauh dengan Aplikasi Google Class terhadap Hasil Belajar Mahasiswa dalam Mata Kuliah Pengembangan Kurikulum" di Universitas Nurul Jadid Probolinggo.

\section{METODE}

Penelitian ini menggunakan jenis penelitian kuantitatif dengan metode eksperimen. Penelitian jenis ini dipilih karena peneliti hendak melihat hasil belajar mahasiswa setelah menggunakan atau menerapkan pembelajaran jarak jauh dengan aplikasi google class. Hasil belajar mahasiswa ini dapat dilihat jika hanya menggunakan datadata konkrit yang dapat diamati oleh panca indra. Lebih lanjut data ini harus dapat diukur dengan jelas. Hal tersebut juga diukuatkan oleh pendapat dari Sugiono. (Sugiono, 2015) yang menyampaikan bahwa metode kuantitatif berlandaskan pada filsafat positifisme. Realitas dipandang sebagai sesuatu yang kongkrit, dapat diamati dengan panca indra dapat dikategorikan dalam jenis, bentuk, warna dan prilaku, tidak berubah, dapat diverivikasi. Pendapat tersebut jelas menekankan bahwa penelitian yang berusaha untuk mengukur sesuatu hal, yang dapat dengan jelas diamati dengan panca indra, serta harus dapat diverivikasi maka menggunakan metode kuantitatif. Pemilihan metode kuantitatif juga dilandasi oleh hubungan peneliti dengan yang diteliti, dimana pada penelitian ini posisi peneliti berada diluar obyek penelitian. Penelitian secara obyektif tidak mengenal individuindividu dengan teliti. Sehingga posisi peneliti adalah independen. (Sugiono, 2015) menjelaskan bahwa dalam penelitian kuantitatif kebenaran itu diluar dirinya, sehingga hubungan antara peneliti dengan yang diteliti harus dijaga jaraknya bersifat independen.

Metode penelitian experimen dipilih karena dalam penelitian ini terdapat perlakuanperlakuan atau tretmen yang diberikan yaitu penerapan pembelajaran jarak jauh dengan aplikasi online google class dalam proses pembelajaran. (Sugiono,

2015) menyampaikan bahwa dalam penelitian experimen terdapat perlakuan (tretment). Metode eksperimen dalam penelitian ini adalah true experiment design, pemilihan tersebut digunakan agar peneliti dapat mengontrol bahwa tidak ada variabel-variabel luar yang ikut mempengaruhi variabel independent dalam penelitian ini. Artinya jelas bahwa yang mempengaruhi variabel dependent adalah variabel independent atau dalam hal ini yang mempengaruhi hasil belajar siswa adalah penerapan pembelajaran jarak jauh dengan aplikasi online google class. " Dikatakan true experiment design (ekperimen yang benar-benar) karena dalam desain ini, peneliti dapat mengontrol semua variabel luar yang mempengaruhi jalannya eksperimen" (Sugiono, 2015). Metode eksperimen yang digunakan dalam true experiment design adalah metode posttest only control design. (Sugiono, 2015) menyampaikan bahwa dalam desain ini terdapat dua kelompok yang masing-masing dipilih secara random (R). Kelompok pertama diberi perlakuan (X) dan kelompok yang lain tidak. Kelompok yang diberi perlakuan disebut kelompok experimen dan kelompok yang tidak diberi perlakuan disebut kelompok kontrol. Selanjutnya untuk melihat pengaruh adanya perlakuan adalah $(\mathrm{O} 1: \mathrm{O} 2)$. Dalam penelitian ini pengaruh dari penerapan media dianalisis dengan menggunakan uji beda, menggunakan statistik t-test. Dan jika terdapat perbedaan yang signifikan antara kelompok experiment dan kelompok kontrol maka dapat dikatan bahwa perlakuan memberikan pengaruh secara signifikan. Untuk lebih memperjelas, berikut ini merupakan table experiment dengan metode posttest-only control design.

\section{Keterangan:}

\section{R : Kelompok Random}

Q2 : Hasil tes akhir kelompok experimen yang diberikan perlakuan

Q4 : Hasil tes akhir kontrol yang tidak diberikan perlakuan

$\mathrm{X}$ : Perlakuan

\section{TEKNIK ANALISIS DATA}

Data yang didapat dalam penelitian ini berupa angka-angka yang didapatkan dari posttest kepada kelompok kontrol dan kelompok experimen. Pada analisis dilakukan Uji normalitas, Uji homogenitas, Uji anova dan Uji $\mathrm{T}$. Uji normalitas digunakan untuk mengetahui data yang akan dianalisis berdistribusi normal atau tidak. Maka digunakan uji Liliefors. Berdasarkan sampel maka akan diuji hipotesis nol dan hipotesis alternatifnya, yaitu: a). Ho : Sample berasal dari populasi berdistribusi normal. Ha : sample tidak berasal dari populasi berdistribusi normal. Langkah-langkah pengujiannya adalah sebagai berikut: 1). 
Pengematan $\mathrm{x} 1, \mathrm{x} 2, \mathrm{x} 3, \ldots, \mathrm{xn}$ dijadikan bentuk baku z1, z2, z3, .. ,zn dengan menggunakan rumus (masing-masing merupakan rata-rata dan simpangan baku sampel) untuk tiap bilangan baku ini dan menggunakan daftar distribusi normal baku, kemudian dihitung peluangnya: $\mathrm{F}(\mathrm{zi})=\mathrm{P}(\mathrm{z} \leq$ zi). 2). Hitung proporsi $z 1, z 2, z 3, \ldots$, zn yang $\leq$ zi. Jika proporsi ini dinyatakan oleh S(zi) maka: Hitung selisih F (zi) - S (zi) kemudian tentukan harga mutlaknya. 3). Ambil harga yang paling besar diantara harga-harga mutlak selisih tersebut, sebutlah harga terbesar ini L0. Untuk menerima atau menolak H0. Kita bandingkan 10 ini dengan nilai L table. Dengan taraf signifikan $\alpha=5 \%$, maka terima H0 jika L0 < L table (sudjana, 2013: 466-467).

Uji homogenitas digunakan untuk menguji kesamaan varians dua populasi yang berdistribusi normal. Tepatnya misalkan dipunyai dua buah populasi berdistribusi normal masing-masing dengan varians dan akan diuji hipotesis varians homogen dan varians tidak homogen. Statistik yang digunakan untuk menguji hipotesis $\mathrm{H} 0$ adalah: $\mathrm{F}=$ dengan kriteria pengujian, tolak $\mathrm{H} 0$ hanya jika $\mathrm{F} \geq \mathrm{F} \alpha(\mathrm{v} 1, \mathrm{v} 2)$ didapat baru daftar distribusi $F$ dengan peluang $\alpha$, sedangkan derajat kebebasan v1 dan v2 masing-masing sesuai dengan $\mathrm{dk}$ pembilang dan penyebut serta $\alpha=$ taraf nyata. (Sudjana, 2013;250).

Dalam Uji Hipotesis teknik yang digunakan untuk menguji hipotesis dalam penelitian ini adalah teknik T-test. Yang diuji adalah perbedaan antara Q2 dengan Q4. Kalau terdapat perbedaan dimana Q2 lebih besar dari Q4 maka berpengaruh positif. Uji ini digunakan untuk mengetahui hasil belajar kelas eksperimen dengan kelas kontrol. Hipotesis dalam penelitian ini adalah: $\mathrm{H} 0: \mu 1$ $=\mu 1$ dan $\mathrm{Ha}: \mu 2>\mu 2$. Pengujian $\mathrm{H} 0$ dilakukan dengan langkah-langkah sebagai berikut. Jika $\mathrm{t}>\mathrm{t} 1-\alpha$ maka $\mathrm{H} 0$ diterima, berarti hasil belajar kelompok experimen dengan aplikasi google class lebih baik dari pada kelompok kontrol.

\section{HASIL DAN PEMBAHASAN}

Hasil belajar mahasiswa diukur dengan menggunakan observasi saat proses pembelajaran dan pemantauan kegiatan mahasiswa dalam mengirim tugas dan diskusi melalui Goggle Class.
Tabel 1. Hasil analisis deskriptif hasil belajar mahasiswa

\begin{tabular}{lcccc}
\hline Statistik & \multicolumn{2}{c}{ Kontrol } & \multicolumn{2}{c}{ Eksperimen } \\
\cline { 2 - 5 } & Pra & Pasca & Pra & Pasca \\
\hline Minimum & 107,0 & 109,0 & 105,0 & 106,0 \\
& 0 & 0 & 0 & 0 \\
\hline Maximu & 144,0 & 148,0 & 143,0 & 156,0 \\
m & 0 & 0 & 0 & 0 \\
\hline SD & 10,79 & 12,65 & 12,75 & 14,71 \\
\hline Mean & 122,4 & 127,3 & 123,8 & 139,2 \\
& 5 & 8 & 8 & \\
\hline
\end{tabular}

Hasil analisis deskriptif motivasi belajar mahasiswa sebelum perlakuan menunjukkan nilai rata-rata di kelas kontrol $(122,45)$ dan kelas eksperimen $(123,88)$ dengan perbedaan 1,43. Perbedaan dalam nilai rata-rata motivasi belajar mahasiswa setelah perlakuan mengalami peningkatan yang signifikan, yaitu sebesar menjadi 4,93 di kelas kontrol, sedangkan kelas eksperimen berjumlah 15,38. Dengan demikian, motivasi belajar mahasiswa di kelas kontrol dan kelas eksperimen diklasifikasikan sebagai kategori baik, tetapi dengan penerapan model kelas google rata-rata motivasi siswa di kelas eksperimen lebih tinggi dari rata-rata dikelas kontrol dengan pembelajaran konvensional.

Tabel 2. Hasil Motivasi Belajar ANOVA untuk Mahasiswa

\begin{tabular}{lcccc}
\hline \multirow{2}{*}{ Statistik } & \multicolumn{2}{c}{ Kontrol } & \multicolumn{2}{c}{ Eksperimen } \\
\cline { 2 - 5 } & Pra & Pasca & Pra & Pasca \\
\hline Minimum & 108,0 & 110,0 & 106,0 & 107,0 \\
& 0 & 0 & 0 & 0 \\
\hline Maksimu & 143,0 & 147,0 & 142,0 & 155,0 \\
m & 0 & 0 & 0 & 0 \\
\hline SD & 11,57 & 11,85 & 11,95 & 11,67 \\
\hline Mean & 121,6 & 126,7 & 122,8 & 135,1 \\
& 8 & 2 & 3 & 5 \\
\hline
\end{tabular}

Hasil analisis deskriptif minat mahasiswa dalam belajar sebelum perawatan menunjukkan nilai rata-rata dikelas kontrol $(121,68)$ dan kelas eksperimen $(122,83)$ dengan perbedaan 1,15 . Perbedaan rata-rata nilai motivasi belajar mahasiswa setelah perlakuan mengalami peningkatan yang signifikan, yaitu sebesar 5,04 di kelas kontrol, sedangkan kelas eksperimen berjumlah 12,32. Dengan demikian, minat mahasiswa dalam belajar dikelas kontrol dan kelas eksperimen tergolong baik, tetapi dengan penerapan model kelas google minat belajar rata-rata siswa di kelas eksperimen lebih tinggi daripada rata-rata di kelas kontrol dengan pembelajaran konvensional. 
Tabel 3. Hasil ANOVA untuk Minat Mahasiswa dalam Belajar

\begin{tabular}{clccc}
\hline $\begin{array}{c}\text { Treatme } \\
\mathbf{n}\end{array}$ & Class & Mean & F & P \\
\hline Pra & Control & 122,4 & 0,19 & 0,76 \\
& & 5 & 7 & 2 \\
& Experime & 123,8 & & \\
& $\mathrm{n}$ & 8 & & \\
\hline pasca & Control & 127,3 & 7,23 & 0,03 \\
& & 8 & 8 & 9 \\
& Experime & 139,2 & & \\
& $\mathrm{n}$ & 6 & & \\
\hline
\end{tabular}

Hasil tes ANOVA menunjukkan nilai signifikansi minat belajar siswa sebelum perawatan $0,713(\mathrm{p}>0,05)$ sehingga tidak ada perbedaan antara kelas kontrol dan kelas eksperimen. Nilai signifikansi minat siswa dalam belajar setelah perawatan adalah 0,035 ( $p<0,05)$ sehingga ada perbedaan antara kelas kontrol dan kelas eksperimen. Dapat disimpulkan bahwa Ho ditolak dan $\mathrm{Ha}$ diterima, jadi ada pengaruh model kelas google pada minat siswa dalam belajar.

\section{KESIMPULAN}

Berdasarkan hasil penelitian dapat disimpulkan bahwa: 1). Terdapat perbedaan motivasi dan minat belajar mahasiswa sebelum dan sesudah menerapkan kelas google dengan peningkatan nilai signifikansi 4,93 ke 5,04 di kelas kontrol, sedangkan kelas eksperimen adalah 12,32 hingga 15,38. Motivasi dan minat mahasiswa dalam belajar lebih baik dengan menerapkan model kelas google; 2). Di sana adalah perbedaan motivasi belajar mahasiswa yang menerapkan kelas google dengan nilai signifikansi 0,039 ( $p<0,05)$. Motivasi belajar mahasiswa dengan pembelajaran model kelas google lebih baik daripada motivasi belajar mahasiswa dengan pembelajaran konvensional; dan 3). ada perbedaan minat belajar mahasiswa menerapkan kelas google dengan nilai signifikansi 0,035 ( $p<0,05$ ). Minat belajar mahasiswa dengan google pembelajaran model kelas lebih baik daripada motivasi belajar mahasiswa dengan pembelajaran konvensional.

\section{DAFTAR PUSTAKA}

Amalia, Farah Fadhilah \& Rachmawati, Rini, 2013. Pemanfaatan Teknologi Informasi Dan Komunikasi Oleh Tenaga Kerja Indonesia Serta Pengaruhnya Terhadap Perubahan Sosial Budaya Di Kampung Pandan Dalam, Ampang Jaya, Malaysia. Jurnal Bumi Indonesia, p. 207.
Budiana, 2015. Pemanfaatan Teknologi Informasi dan Komunikasi dalam Pembelajaran bagi Para Guru SMP 2 Kawali Desa Citeureup Kabupaten Ciamis. Jurnal Aplikasi Ipteks untuk Masyarakat, p. 62.

Budiman, H., 2017. Peran Teknologi Informasi Dan Komunikasi Dalam Pendidikan. Al-Tadzkiyyah: Jurnal Pendidikan Islam, p. 31.

Abdurahman. (2017). Implikasi UUSPN Terhadap Pendidikan Islam Implikasi. Al-Tanzim : Jurnal Manajemen Pendidikan Islam, 1(1), 19-35.

Muali, C., Islam, S., Bali, M. E. I., Hefniy, Baharun, H., Mundiri, A., ... Fauzi, A. (2018). Free Online Learning Based On Rich Internet Applications; The Experimentation Of Critical Thinking About Student Learning Style. Journal of Physics: Conference Series, 1114, 012024. https://doi.org/10.1088/17426596/1114/1/012024

Satya, 2014. Penerapan Teknologi Pendidikan Tingkatkan Minat Belajar, e-paper: neraca.co.id.

Slameto, 2010. Belajar dan Faktor-faktor yang mempengaruhinya. In: s.1.:PT Rineka Cipta.

Sugiono, P. D., 2015. Metode Penelitian Kuantitatif dan Kualitatif. Bandung: Alfabeta.

Arikunto, suharsini. 2006. Prosedur Penelitian Suatu Pendekatan Praktik. Jakarta: Rinika Cipta.

Arsyad, Azhar. 2013. Media Pembelajaran. Depok: PT Rajagrafindo Persada

Daryanto. 2013. Media Pembelajaran Perannya Sangat Penting Dalam Mencapai Tujuan Pembelajaran. Yogyakarta: Gava Media

Rianto, Milan. 2007. Pengelolaan kelas Model Pakem. Jakarta: Dirjen PMPTK depdiknas

Rusman. 2015. Pembelajaran Tematik Terpadu Teori Praktik dan Penilaian. Jakarta: PT Raja Grafindo Persada

Slameto. 2013. Belajar \& Faktor- fakktor yang mempengaruhinya

Sugeng. A.Y. Ysh. 2006. Dasar-dasar Penelitian. Semarang: Ikip Semarang Press

Sudjana, Nana. 2013. Tuntunan Penyusunan Karya Ilmiah. Bandung: Sinar Baru Algensindo Offset

Sudjana, Nana dan Rivai, Ahmad. 2011. Media Pengajaran. Bandung: Sinar Baru Algensindo Offset. 